\title{
Study on inorganic coat
}

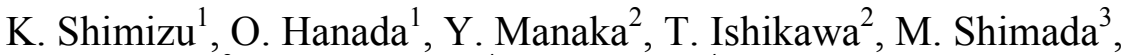 \\ N. Kusakabe ${ }^{3}$, M. Takezawa ${ }^{4} \&$ H. Gotoh ${ }^{4}$ \\ ${ }^{I}$ New Nippon Paint Co. Ltd., Japan \\ ${ }^{2}$ Nihon Chuo Kenkyujo, Japan \\ ${ }^{3}$ Sketch Co. Ltd., Japan \\ ${ }^{4}$ Nihon University, Japan
}

\begin{abstract}
Global warming refers to the increase in the average temperature of the earth's near-surface atmosphere and oceans that has occurred since the mid-20th century and is projected to continue. Climate model projections summarized in the latest Intergovernmental Panel on Climate Change report indicate that the global surface temperature will probably rise a further $1.1 \sim 6.4^{\circ} \mathrm{C}$ during the $21 \mathrm{st}$ century. Mitigation of global warming can be accomplished through reductions in the rate of anthropogenic greenhouse gas release. The main influence on the surface temperature of the earth is solar radiation. Sustainability is realized by considering harmony between the environment and society. The consumption of energy will be reduced if the temperature of rooms can be controlled without any air conditioning, and heat island effects will be reduced. Assuming that electromagnetic waves with a certain range of frequencies are scattered to shield the radiated heat energy in the insulation, the intensity of scattered light for a set of packed spheres can be calculated using the Mie theory. As a result, the heat shield coating, AdgreencoatEX, and the energy saving glass coat, Glass Coat, were developed based on the reflection and permeability of scattered light in a set of packed spheres. AdgreencoatEx is a high-reflection coating that effectively reflects the near infrared range of solar radiation and suppresses the buildup of heat on roof surfaces. Glass Coat is effective for windows of commercial buildings and private houses. This protective coat is directly applied to a windowpane to shut out heat and ultraviolet rays. Infrared rays are reduced and ultraviolet rays are almost completely shut out to prevent deterioration of objects inside rooms.
\end{abstract}


Keywords: global warming, scattered light, heat shield coating, energy saving glass coat.

\section{Introduction}

The leaders of Australia, Brazil, Canada, the European Union, France, Germany, India, Indonesia, Italy, Japan, the Republic of Korea, Mexico, Russia, South Africa, the United Kingdom, and the United States have met and agreed as follows: (1) Climate change poses a clear danger requiring an extraordinary global response. (2) This response should prioritize the economic and social development of developing countries. (3) Moving to a low-carbon economy represents an opportunity to promote continued economic growth and sustainable development. (4) There is an urgent need to develop and deploy new clean energy technologies at the lowest possible cost. (5) The response must involve balanced attention to mitigation and adaptation.

We reaffirm the objectives, provisions and principles of the UN Framework Convention on Climate Change. Recalling the Major Economics Declaration adopted in Toyako, Japan in July 2008, and taking full account of decisions taken in Bali, Indonesia, in December 2007, we resolve to spare no effort to reach agreement in Copenhagen, both with each other and with other Parties, on further implementation of the Convention [1].

The Major Economies Forum on Energy and Climate took place in L'Aquila, Italy, on July 9, 2009, and the following declaration was made:

"Climate change is one of the greatest challenges of our time. As leaders of the world's major economics, both developed and developing, we intend to respond vigorously to this challenge" [2].

The Prime Minister of Japan, Yukio Hatoyama, stated the following at the United Nations Summit on Climate Change on 22 September, 2009:

"Based on the discussion in the Intergovernmental Panel on Climate Change (IPCC), I believe that the developed countries need to take the lead in emissions reduction efforts. It is my view that Japan should positively commit itself to setting a long-term reduction target. For its mid-term goal, Japan will aim to reduce its emissions by $25 \%$ by 2020 , if compared to the 1990 level, consistent with what the science calls for in order to halt global warming" [3].

The 2009 United Nations Climate Change Conference, commonly known as the Copenhagen Summit, was held at the Bella Center in Copenhagen, Denmark, on December 7-18, 2009. The conference included the $15^{\text {th }}$ Conference of the Parties (COP15) to the United Nations Framework Convention on Climate Change and the $5^{\text {th }}$ Meeting of the Parties (COP/MOP5) to the Kyoto Protocol. According to the Bali Road Map, a framework for climate change mitigation beyond 2012 was to be agreed there. The Copenhagen Accord was drafted by the United States, China, India, Brazil and South Africa on December 18, and judged a "meaningful agreement" by the United States government. It was "recognized", but not "agreed upon", in a debate of all the participating countries the next day, and it was not passed unanimously. The document recognized that 
climate change is one of the greatest challenges at present and that actions should be taken to keep any temperature increases to below $2^{\circ} \mathrm{C}$ [4].

The report of the Intergovernmental Panel on Climate Change in 1995 states that the average temperature on the earth increased by about $0.3 \sim 0.6^{\circ} \mathrm{C}$ over the past 100 years, and that global warming will further advance if no new measures are taken, raising the average temperature at the end of the $21^{\text {st }}$ century by about $2^{\circ} \mathrm{C}$ (minimum: about $1^{\circ} \mathrm{C}$; maximum: about $3.5^{\circ} \mathrm{C}$ ), and further in the future. An increase of $2^{\circ} \mathrm{C}$ is not to be dismissed as "only" $2^{\circ} \mathrm{C}$; the scorching heat wave in Japan in 1994 was, in fact, an increase of "only" $1^{\circ} \mathrm{C}$ above the temperature of an average year. While the energy consumed for wintertime heating will be reduced due to global warming, that consumed for summertime air conditioning will increase. In urban areas, local temperature rises (heat island phenomenon) will increase due to concentrated energy use, and large increases will also occur in water usage and energy consumption [5].

\section{Energy consumption and urban heat islands}

In 2008 , the total worldwide energy consumption was 474 exajoules $\left(5 \times 10^{20} \mathrm{~J}\right)$ with 80 to 90 percent of this energy derived from the combustion of fossil fuels. This is equivalent to an average power consumption rate of 15 terawatts $(1.504 \mathrm{x}$ $\left.10^{13} \mathrm{~W}\right)$. Not all of the world's economics track their energy consumption with the same rigor, and the exact energy content of a barrel of oil or a ton of coal will vary with quality. Most of the world's energy resources ultimately have their origin in sunlight hitting the earth. Some of that energy has been preserved as fossil energy, and some is directly or indirectly usable, via wind, hydro- or wave power, for example. The term solar constant refers to the amount of incoming solar electromagnetic radiation per unit area, measured on the outer surface of Earth's atmosphere, in a plane perpendicular to the rays. The solar constant includes all types of solar radiation, not just visible light. It has been determined by satellite measurements to be roughly 1366 watts per square meter, though it fluctuates by about $6.9 \%$ during a year - from $1412 \mathrm{Wm}^{-2}$ in early January to $1321 \mathrm{Wm}^{-2}$ in early July, due to the Earth's varying distance from the sun, and by a few parts per thousand from day to day. For the entire Earth, with a cross section of $127,400,000 \mathrm{~km}^{2}$, the total energy rate is 174 petawatts $(1.740 \mathrm{x}$ $10^{17} \mathrm{~W}$ ), plus or minus $3.5 \%$. This value is the total rate of solar energy received by the planet; about half of this, $89 \mathrm{PW}$, reaches the Earth's surface [6].

An urban heat island is a metropolitan area which is significantly warmer than the surrounding rural areas. The temperature difference is usually larger at night than during the day, and is most apparent when winds are weak. Urban heat islands appear during both the summer and winter, and they are largely due to modification of the land surface by urban development using materials that effectively retain heat. Waste heat generated by energy usage is a secondary contributor. As population centres grow they tend to modify a greater and greater area of land, causing a corresponding increase in average temperature. Not all cities have a distinct urban heat island. Mitigation of the urban heat island effect can be accomplished through the use of green roofs and light-coloured surfaces 
in urban areas, which reflect more sunlight and absorb less heat. The heat island effect can be counteracted slightly by using white or reflective materials to build houses, pavements, and roads, thus increasing the overall albedo of the city. Using light-coloured concrete has proven effective in reflecting up to $50 \%$ more light than asphalt and reducing ambient temperatures. Materials with a low albedo value, such as black asphalt, absorb a large percentage of solar heat and contribute to the warming of cities. By both paving and replacing asphalt with light-coloured concrete, communities can lower their average temperature [7].

The earth receives 174 petawatts of incoming solar radiation in the upper atmosphere. Approximately $30 \%$ is reflected back to space while the rest is absorbed by clouds, oceans and land masses. The spectrum of solar light at the earth's surface is mainly spread across the visible and near-infrared ranges with a small part in the near-ultraviolet [8].

\section{Electromagnetic waves scattered by fine ceramic spheres}

It is well known that insulation raises the room temperature in buildings and that electric-power supply crises are regularly caused by the use of air conditioning during high summer. The use of air conditioning should be reduced to alleviate heat island effects. Atoms and molecules constituted a body are hardly moved by the resonance when the electromagnetic wave rises. Therefore, it is thought that increases in temperature can be prevented if the light can be blocked. We consider the case where solar energy is prevented from penetrating a layer of paint due to scattering of the sunlight by fine ceramic spheres, as proposed by Mie $[9,10]$. For a two-dimensional wave with an amplitude of 1 , incident on a sphere (II) with an electrical conductivity $\sigma$ and a relative permittivity $\varepsilon^{(\mathrm{II})}$ from an insulator (I) having a relative permittivity $\varepsilon^{(\mathrm{I})}$, the scattered wave is described by the spherical coordinates $(\mathrm{r}, \theta, \phi)$ as shown in Figure 1 and equations (1-1), (1-2), and (1-3).

$$
\begin{aligned}
& \mathrm{E}_{\mathrm{r}}^{(\mathrm{s})}=\left(1 / \kappa^{(\mathrm{I}) 2}\right)\left(\cos \varphi / \mathrm{r}^{2}\right) \Sigma \mathrm{l}(\mathrm{l}+1)^{\mathrm{e}} \mathrm{B}_{\imath} \zeta_{\imath}^{(1)}\left(\mathrm{k}^{(\mathrm{I})} \mathrm{r}\right) \mathrm{P}_{\mathrm{\imath}}^{(1)}(\cos \theta) \\
& \mathrm{E}_{\theta}{ }^{(\mathrm{s})}=-\left(1 / \kappa^{(\mathrm{I})}\right)(\cos \varphi / \mathrm{r}) \Sigma\left[{ }^{\mathrm{e}} \mathrm{B}_{\imath} \zeta_{1}^{(1)^{\prime}}\left(\mathrm{k}^{(\mathrm{I})} \mathrm{r}\right) \mathrm{P}_{\imath}^{(1)^{\prime}}(\cos \theta) \sin \theta\right. \\
& \left.-i^{\mathrm{m}} \mathrm{B}_{\iota} \zeta_{\mathrm{l}}^{(1)}\left(\mathrm{k}^{(\mathrm{I})} \mathrm{r}\right) \mathrm{P}_{\mathrm{l}}^{(1)}(\cos \theta)(1 / \sin \theta)\right] \\
& \mathrm{E}_{\varphi}{ }^{(\mathrm{s})}=-\left(1 / \kappa^{(\mathrm{I})}\right)(\sin \varphi / \mathrm{r}) \Sigma\left[{ }^{\mathrm{e}} \mathrm{B}_{\iota} \zeta_{\mathrm{l}}^{(1)^{\prime}}\left(\mathrm{k}^{(\mathrm{I})} \mathrm{r}\right) \mathrm{P}_{\imath}{ }^{(1)}(\cos \theta)(1 / \sin \theta)\right. \\
& \left.-\mathrm{i}^{\mathrm{m}} \mathrm{B}_{\imath} \zeta_{\imath}^{(1)}\left(\mathrm{k}^{(\mathrm{l})} \mathrm{r}\right) \mathrm{P}_{1}^{(1)^{\prime}}(\cos \theta) \sin \theta\right]
\end{aligned}
$$

Here $E^{(s)}$ is the electric field of the scattered wave, $\zeta$ is the third Bessel function of Riccati, $\mathrm{P}$ is the adjacent Legendre function, $\mathrm{B}$ is a complex function, and ' ' ' and $\mathrm{P}^{\prime}$ are first derivatives of $\zeta$ and $\mathrm{P}$.

As an example, Figure 2 shows the intensity of a scattered wave at a distance $\mathrm{r}=1000 \mu \mathrm{m}$ from spheres of radius $\mathrm{a}=0.3$ and $0.5 \mu \mathrm{m}$, where (I) corresponds to air, (II) corresponds to silica, $\varepsilon^{(\mathrm{I})}=1.0, \varepsilon^{(\mathrm{II})}=11.9, \sigma=2.52 \times 10^{4} /(\mathrm{m} \cdot \Omega)$, and the 
velocity of light in a vacuum is $\mathrm{c}=3.0 \times 10^{8} \mathrm{~m} / \mathrm{s}$. It is clear that the scattered wave intensity from the sphere of radius $0.5 \mu \mathrm{m}$ is larger than from the sphere of radius $0.3 \mu \mathrm{m}$, and the latter case corresponds almost to perfect elastic scattering, where the scattered wave has an amplitude of 1 .

Figures 3 and 4 show solid-geometry representations of the strength of the scattered wave at $\mathrm{r}=0.1 \mu \mathrm{m}$ from spheres of radii $\mathrm{a}=0.3$ and $0.5 \mu \mathrm{m}$, respectively.

We next consider scattering from many fine silica spheres embedded within a layer of paint. Figure 5 shows the arrangement of the spheres. The scattered wave intensity from each sphere is calculated using the spherical coordinates $(\mathrm{r}$, $\theta, \phi)$, taking the centre of that sphere as the origin. The overall profile of scattering intensity was calculated by adding the profiles of individual spheres following $\mathrm{x}-\mathrm{y}$ coordinate transformation, assuming a single layer of spheres arranged in a $0.1 \times 0.1 \mathrm{~mm}^{2}$ area.

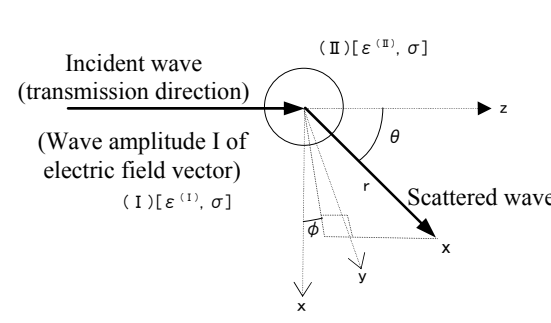

Figure 1: $\quad$ Model of a scattered wave [9].

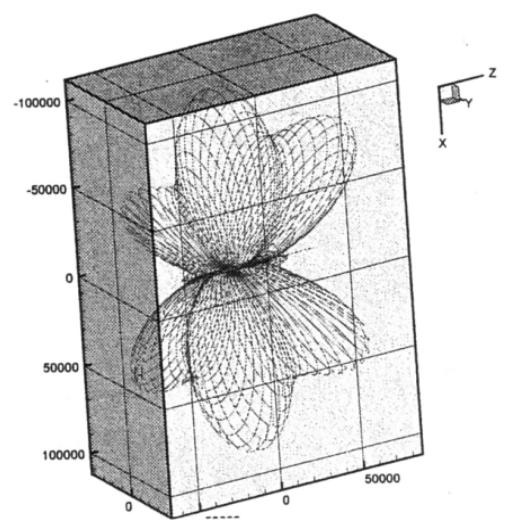

Figure 3: Intensity of a scattered wave $(\mathrm{r}=0.1 \mu \mathrm{m}, \mathrm{a}=$ $0.3 \mu \mathrm{m})[9]$.

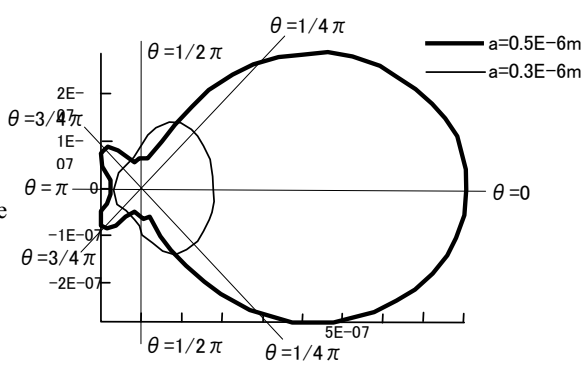

Figure 2: Intensity of a scattered wave at $\mathrm{r}=1000 \mu \mathrm{m}$ [9].

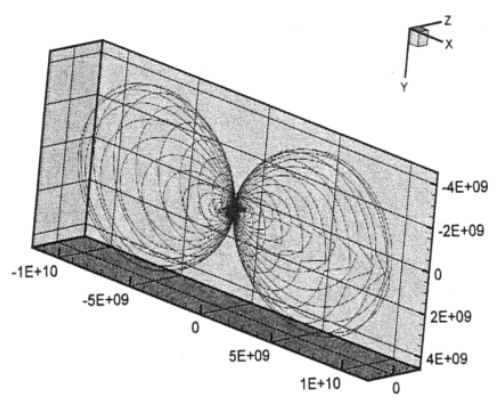

Figure 4: Intensity of a scattered wave $(\mathrm{r}=0.1 \mu \mathrm{m}, \mathrm{a}=$ $0.5 \mu \mathrm{m})[9]$. 


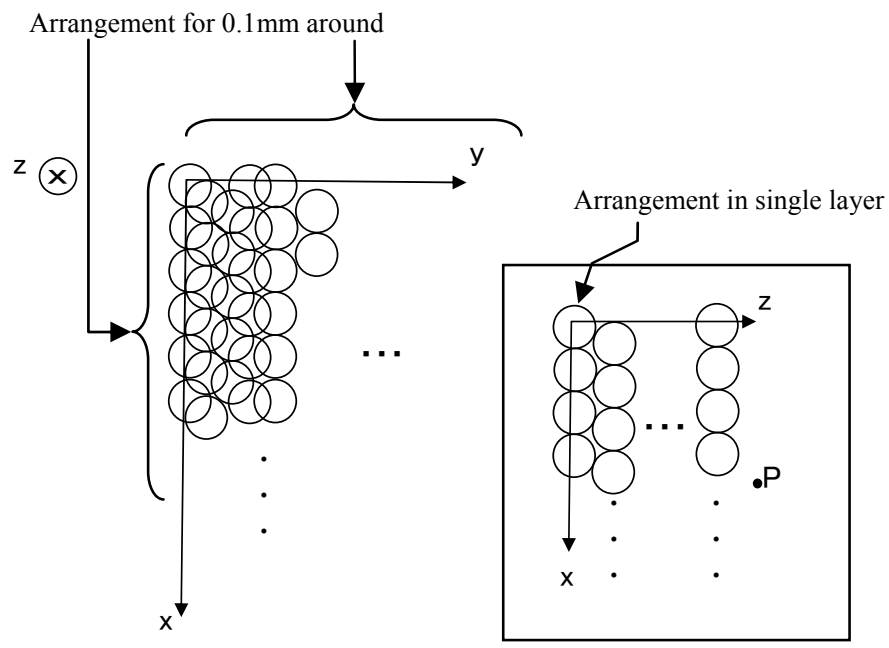

Figure 5: $\quad$ Arrangement of spheres [9].

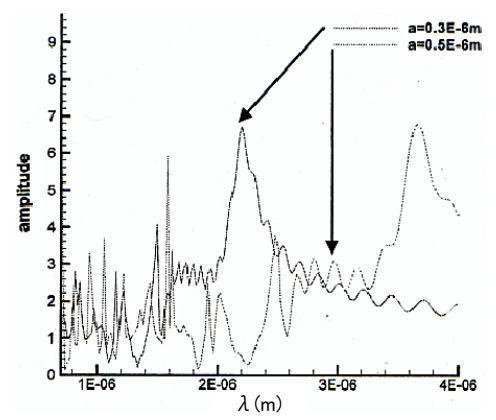

Figure 6: Composite wave amplitude [9].

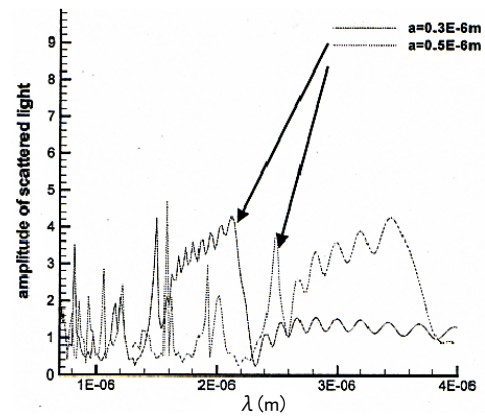

Figure 7: Scattered wave amplitude [9].

Figure 6 shows the combined incident and scattered wave amplitudes as a function of the wavelength $\lambda$ of the incident light for spheres of radius 0.3 and $0.5 \mu \mathrm{m}$. Figure 7 shows the scattered wave amplitudes for $\mathrm{a}=0.3$ and $0.5 \mu \mathrm{m}$. It is clear that the scattered wave is influenced by the incident wavelength $\lambda$ and the sphere radius a in Figure 6 and Figure 7.

\section{Applied products}

A highly-reflective heat shield coating, AdgreencoatEX, and an energy saving glass coat, Glass Coat, have been developed based on the above concepts. 


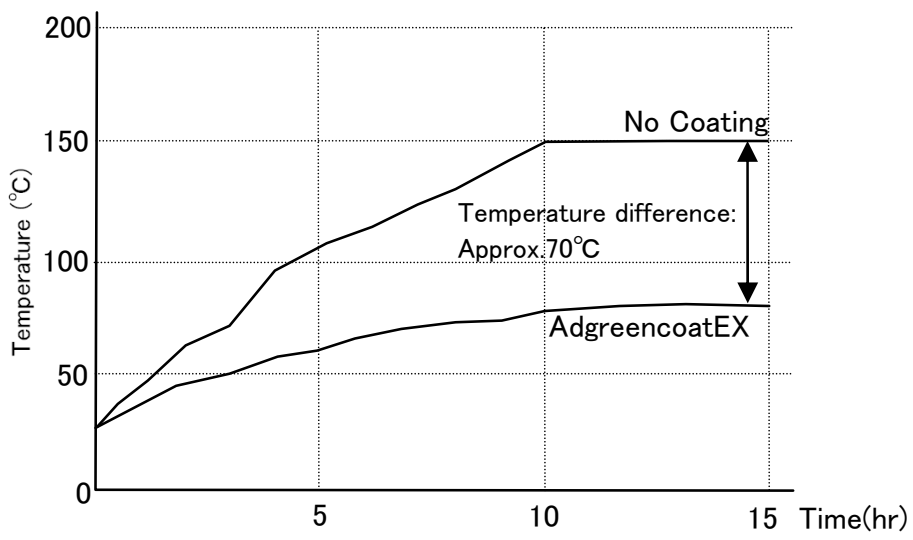

Figure 8: Relation between exposure time and surface temperature.

\subsection{Properties of AdgreencoatEX}

The extraordinary property of AdgreencoatEX is that the surface temperatures in heat islands can be made the same as in "green space". In tests carried out by exposing galvanized steel sheets $(250 \mathrm{~mm} \times 265 \mathrm{~mm})$ with and without an AdgreencoatEX (EX-009: white colour) coating to a $500 \mathrm{~W}$ halogen lamp, the surface temperature measured by an infrared thermometer (Raytek Japan; Minitemp MT4) after 15 minutes of exposure was lower by an amazing $70^{\circ} \mathrm{C}$ for the coated steel (see Figure 8).

The unique heat-shielding capability that only AdgreencoatEX possesses makes a positive contribution to the global environment. AdgreencoatEX is composed of high-purity fine spherical grains with a sharp grain-size distribution, and offers advanced solar radiation reflection and infrared exhaust capabilities in addition to being weather-resistant and durable. It reflects most forms of light, heat, and infrared rays. Furthermore, because of its ability to release the slight amount of heat it absorbs, there is no heat buildup. AdgreencoatEX is a groundbreaking coating that requires no finish. The coating can be applied in just three steps, thus reducing both cost and working time. Solar reflectivity tests were carried out on AdgreencoatEX on August 23, 2007. The test body was Adgreencoat EX-012 (Wet $150 \mu \mathrm{m}$ applicator: greyish colour). The spectral reflectivity (300 2500 nm wavelength) of the test piece (50 $\times 50 \times 1 \mathrm{~mm}$ ) was measured using a large scale materials testing laboratory spectrophotometer (Shimadzu Corporation; UV-3150), and the solar reflectivity was then calculated according to JIS R 3106-1998 "Testing method on transmittance, reflectance and emittance of flat glasses and evaluation of solar heat gain coefficient". However, using barium sulfate as the standard test material for measuring spectral reflectivity, we measured the diffuse reflection (including spectral elements) at an $8^{\circ}$ angle of incidence. The results are shown in Table 1 and Figure 9. 
We evaluated the ability of AdgreencoatEX to suppress increases in temperature by coating it onto external walls of a facility. We used two similar facilities, coating one with AdgreencoatEX and leaving the other with no coating, and performed temperature measurements on the same days and times of day. The external wall temperature of the coated subject, even though it initially rose to a certain level, immediately fell again because of heat emission. Also, the ceiling and internal temperature remained constant throughout the day despite an increase in the outside temperature. Figure 10 shows the results of temperature measurements using AdgreencoatEX (EX-012: greyish colour) and no coating.

\subsection{Properties of glass coat}

The Glass Coat is applied directly to a windowpane to shut out heat and ultraviolet rays. Infrared rays are reduced and ultraviolet rays are almost completely eliminated from incoming light to prevent deterioration of objects inside rooms.

Table 1: $\quad$ Solar reflectivity.

\begin{tabular}{|c|c|c|c|}
\hline All wavelengths & Visible light range & Near-infrared range & $\begin{array}{c}\text { Top coat } \\
\text { membrane colour }\end{array}$ \\
\hline $54.5 \%$ & $29.8 \%$ & $82.7 \%$ & EX-12 \\
\hline
\end{tabular}

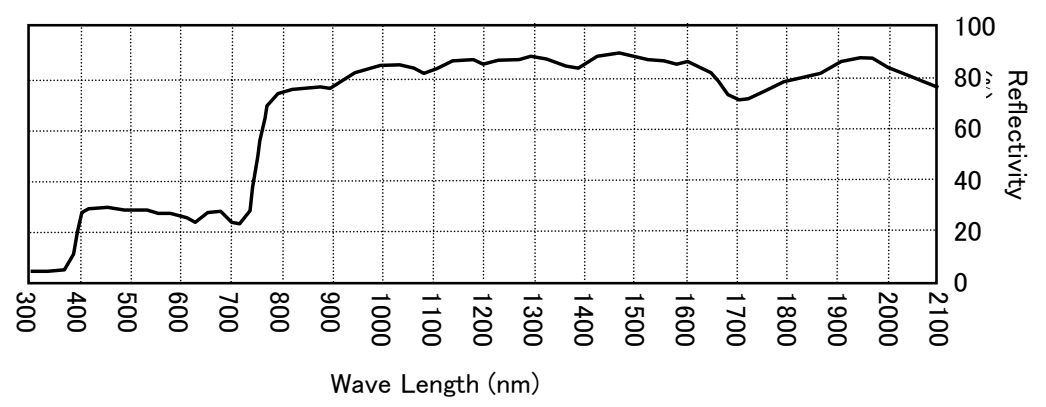

Figure 9: $\quad$ Spectral reflectivity.
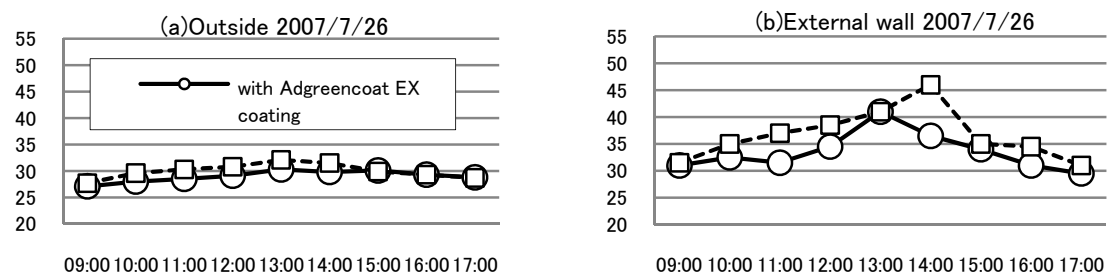

Figure 10: Temperature results when using AdgreencoatEX (EX-012) and no coating. 
Advanced Computational Methods and Experiments in Heat Transfer XI 107

(c)Ceiling 2007/7/26

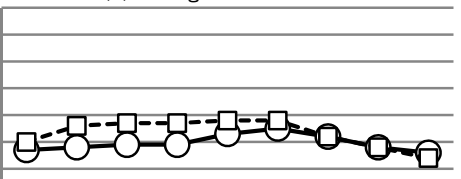

09:00 10:00 11:00 12:00 13:00 14:00 15:00 16:00 17:00

(e)Outside 2007/7/28

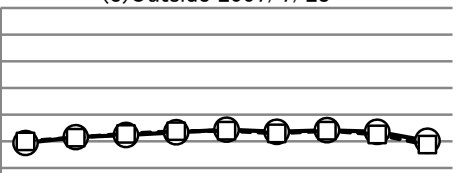

09:00 10:00 11:00 12:00 13:00 14:00 15:00 16:00 17:00

(g)Ceiling 2007/7/28

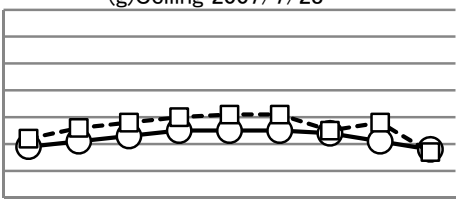

09:00 10:00 11:00 12:00 13:00 14:00 15:00 16:00 17:00

(i)Oustide 2007/8/1

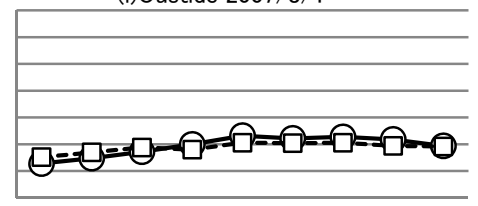

09:00 10:00 11:00 12:00 13:00 14:00 15:00 16:00 17:00

(k)Ceiling 2007/8/1

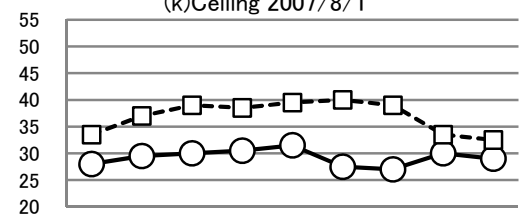

09:00 10:00 11:00 12:00 13:00 14:00 15:00 16:00 17:00 (d) Unternal 2007/7/26

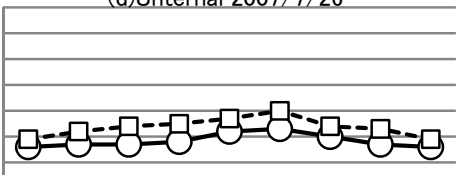

09:00 10:00 11:00 12:00 13:00 14:00 15:00 16:00 17:00

(f)External wall 2007/7/28

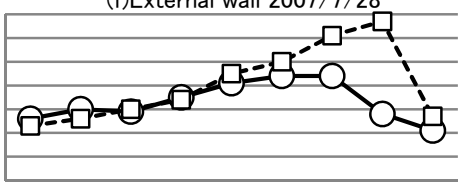

09:00 10:00 11:00 12:00 13:00 14:00 15:00 16:00 17:00

(h)Internal 2007/7/28

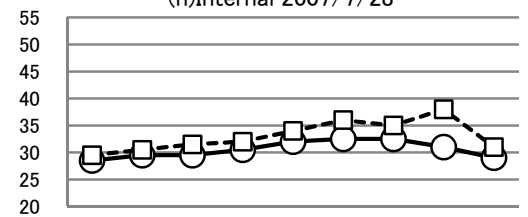

09:00 10:00 11:00 12:00 13:00 14:00 15:00 16:00 17:00

(j)External wall 2007/8/1

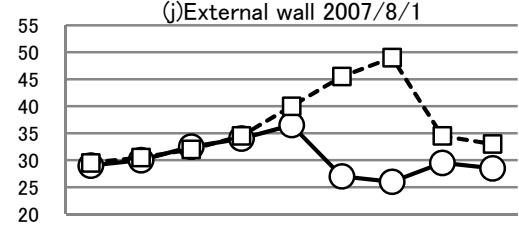

09:00 10:00 11:00 12:00 13:00 14:00 15:00 16:00 17:00

(I)Internal 2007/8/1

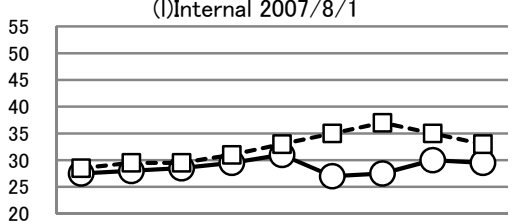

09:00 10:00 11:00 12:00 13:00 14:00 15:00 16:00 17:00

Figure 10: Continued. 


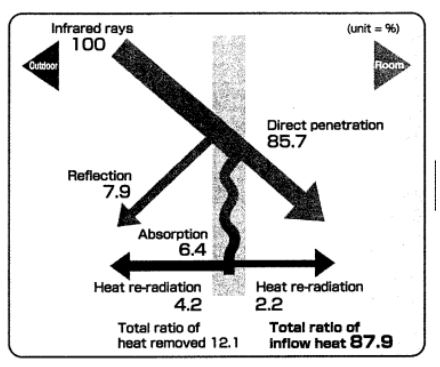

(a)

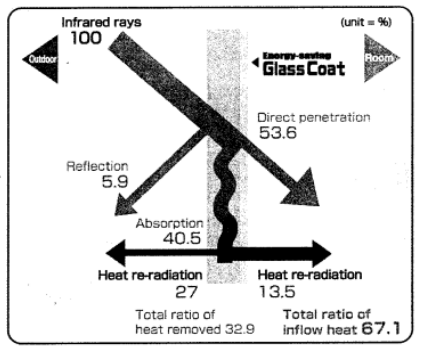

(b)

Figure 11: (a) 3-mm-thick glass only; (b) 3-mm-thick glass + energysaving glass coat.

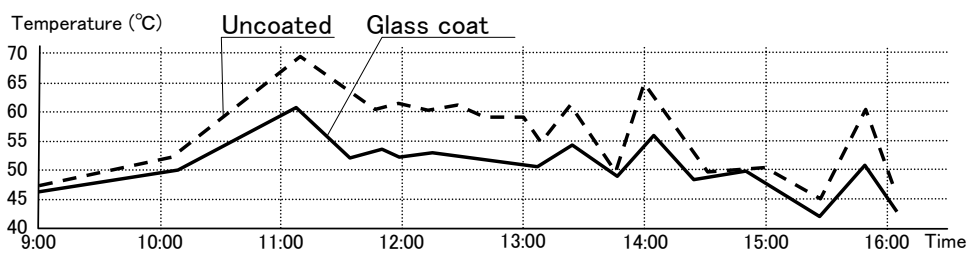

Figure 12: Heat shielding performance of energy-saving glass coat.

The Glass Coat is an energy saving glass coat which can be applied to the windows of buildings, including both commercial establishments and private houses.

Figures 11(a) and 11(b) show a comparison of the optical and thermal pathways for 3-mm-thick glass windows without and with an energy-saving glass coat. Figure 12 shows the heat-shielding performance of the energy-saving glass coat.

The glass coat shuts out $95 \%$ of harmful ultraviolet rays, which are leading causes of skin cancer, wrinkles and blemishes. It also prevents deterioration of merchandise, curtains and carpets caused by ultraviolet rays. Files, moths, and other annoying insects have the habit of gathering around ultraviolet light sources at night. The energy-saving glass coat shuts out light on both sides. It can also reduce outward radiation of ultraviolet rays at night. Keeping insects away makes this product very practical for use in establishments that operate at night, such as restaurants, hotels and food processing plants. As this product is transparent to about $70 \%$ or more of visible light spectrum or visible light intensity passes through it, it will not cause annoying dimming of the views from hotel windows, showrooms, display windows, or living rooms of private homes. In addition, the external view is not distorted in any way since no unevenness exists in energy-saving glass coatings, so that the view is crystal clear even with a large windowpane. The energy-saving glass coat shuts out $30 \%$ or more of the 
infrared rays from the incoming light, suppressing increases in room temperature in summer and improving the efficiency of air conditioning. In winter, it makes it hard for far-infrared rays and thermal energy from heating systems to escape through the windows. The glass coat is a super-hydrophilic and stain-resistant coating that oxidizes grime and prevents the buildup of static electricity. Thus, it has three revolutionary functions: (1) it has been discovered that superhydrophilic particles have powerful self-cleaning characteristics due to the synergistic increase in hydrophilicity that results from both the effect of fractal theory and the nature of the polymers; (2) ultra-fine particles of tin oxide $\left(\mathrm{SnO}_{2}\right)$ have a large number of free electrons and a low electronic resistivity (surface resistivity of $10^{8} \sim 10^{10} \Omega$ per particle). As a result, surfaces coated with tin oxide do not attract ambient dust particles and both dust and exhaust gases find it difficult to attach to the surface; (3) a compound of titanium phosphate that breaks down organic matter with water and air as the only catalyst has been added. This breaks down stains and preserves the hydrophilic effect for a longer period of time. Moreover, the product has proven effective as an antibacterial, anti-mould and deodorizing agent which helps to continuously preserve a clean environment. This anti-stain feature is evident even in the absence of light.

\section{Conclusions}

AdgreencoatEX and Glass Coat are representative of novel energy-saving products that combat global warming and heat island effects. The temperature set by air-conditioning within the building can be reduced by coating AdgreencoatEX on the roof and the outer walls. It is estimated by The Tokyo Electric Power Company that the effect of cutting the room temperature by only $1{ }^{\circ} \mathrm{C}$ is equivalent to reducing the electricity bill by $10 \%$. After Glass Coat is applied on a glass surface, it hardens naturally at room temperature; it feels dry to the touch in 30 minutes. It hardens in 2 days and it is completely hard in 2 weeks. Its hardness is comparable to that of a $4 \sim 5 \mathrm{H}$ pencil. It withstands climate changes and resists degeneration. Cleaning does not produce any scratches on it. It has an astonishingly long service life of 10 years or more. The cost of installation can be recouped by a reduced electricity cost.

\section{References}

[1] Ministry of Foreign Affairs of Japan, Declaration of the Leaders - The Major Economies Forum on Energy and Climate, http://www.mofa.go.jp/mofaj/gaiko/kankyo/kiko/mef-0910.html, 2010.

[2] U.S. Department of State, Major Economies Forum on Energy and Climate, http://www.state.gov/r/pa/prs/ps/2009/sept/129190.htm, 2010.

[3] Prime Minister of Japan and His Cabinet, Statement by Prime Minister Yukio Hatoyama at the United Nations Summit on Climate Change, http://www.kantei.go.jp/foreign/hatoyama/statement/200909/ehat-0922e.html, 2010. 
110 Advanced Computational Methods and Experiments in Heat Transfer XI

[4] Wikipedia, the free encyclopedia, 2009 United Nations Climate Change Conference, http://en.wikipedia.org/wiki/2009-United-Nations-ClimateChange-Conference, 2010.

[5] The APEC Virtual Center for Environmental Technology Exchange, What Results from Global Warming? http://www.epcc.pref.osaka.jp/apec/eng/earth/globalwarming/dounaru.html, 2010.

[6] Wikipedia, the free encyclopedia, World energy resources and consumption, http://en.wikipedia.org/wiki/World-energy-resources-andconsumption, 2010

[7] Wikipedia, the free encyclopedia, Urban heat island, http://en.wikipedia.org/wiki/Urban-heat-island, 2010

[8] Wikipedia, the free encyclopedia, Solar energy, http://en.wikipedia.org/wiki/Solar-energy, 2010

[9] E. Ohkawa, H. Mikada, K. Onishi, K. Tanibuchi, S. Ishibashi and Y. Ashida, A study on electromagnetic waves scattered by fine ceramic spheres, Proceedings of the $118^{\text {th }}$ SEGJ Conference, pp146 149, 2008

[10] Born, M. \& Wolf, E, Principles of optics, Cambridge University Press, 7th ed.1999. 